\title{
The Human Resource Implications of Plant Shutdowns
}

\author{
By JEANNE PRIAL GORDUS
}

\begin{abstract}
Human resource programs that were developed to serve those displaced by plant closings have been fragmented. Participation rates have been low in placement, job search assistance, relocation, and retraining programs, and results have not been particularly positive. Great emphasis was placed upon serving those in need when programs did develop. The fragmentation characteristic of previous policy-or nonpolicyseems to have undergone considerable organization and rationalization with the advent of the Job Training Partnership Act (JTPA) and the association of several major labor-management displaced worker programs with the federal-state program. This change tends to emphasize placement and to focus upon training exclusively. As a result, not only will disadvantaged workers compete with displaced workers for training resources and jobs, but participation in programs for displaced workers will be encouraged for those who are most advantaged, thus consigning a large number of less-advantaged displaced workers to underemployment, permanent unemployment, and eventual dependence upon income maintenance.
\end{abstract}

Jeanne Prial Gordus is a staff member of the Industrial Development Division of the University of Michigan Institute of Science and Technology, where she directs the Employment Transition Program. She received her Ph.D. in economic history from the University of Michigan. Her recent research addresses early retirement, plant shutdowns, and permanent job loss. Her publications include Plant Closings and Economic Dislocation (1981), with Paul Jarley and Louis A. Ferman, and, for the U.S. Congress's Joint Economic Committee, Economic Change, Physical Illness, Mental Illness, and Social Deviance (1984), with Sean McAlinden. 
J $\mathrm{N}$ the past, when a plant shut down1 when there was no longer any hope that concessions or employee buy-outs could save the jobs-what choices did displaced industrial workers have? If they could not retire, they could have done one of three things; reenter the labor market directly, relocate, or retrain. Faced with this same situation and the same limited choices, what have human resource programs done? Sometimes they have attempted to assist displaced workers to reenter the labor market, relocate, or retrain.

What happened as displaced workers from plant closings and human resource programs faced the problems and choices together? Not much.

Why? This article argues that previously developed programs ignored the constraints and resources of displaced workers while workers were either not informed or ignored information about the labor market. Decision making on both sides suffered.

What happened then? Often, more bad decisions resulted.

Why should all this be reviewed? Because plants continue to shut down and workers continue to suffer permanent job loss, as a result of foreign competition, technological change, and industrial restructuring. Unless adequate information, support, and resources are provided and well-informed decision making can take place, we run the risk of the permanent disemployment of hundreds of thousands of American workers even when some jobs are available. We run the risk of training for jobs that will never exist or for jobs that will disappear in a few years. We also run the risk of attributing the blame for prolonged unemployment to workers for not participating in programs when in fact they could not do so. Through this blame, it is also likely that those workers' chances in the labor market will be even further reduced.

\section{LABOR MARKET REENTRY AND JOB SEARCH ASSISTANCE}

The plant-closing policy literature provides an interesting and checkered pattern of search/placement programs, participation levels, and results. A recent review of nine studies shows that participation rates in programs providing placement assistance in plant closings vary widely, ranging from a 1 percent participation rate in a Fort Worth closing to a 70 percent rate in the Mack Truck plant closing. ${ }^{1}$ In general, when data are available about participants and nonparticipants in programs, participants are older -39.2 years versus 37 years - and have higher seniority -11.3 years versus 10.8 years.

Age has long been known to be a critical variable for those who are unemployed. The displaced older workers are unemployed for a longer period, have less successful reemployment experiences, and sometimes fail to gain new employment at all. $^{2}$ Older workers encounter significant barriersboth economic and noneconomic-to relocation, including home ownership and community attachment. Age is also a problem for retraining since the economic returns for retraining will be reduced due to limited time at the new

1. Jeanne Prial Gordus, Paul A. Jarley, and Louis A. Ferman, Plant Closings and Economic Dislocation (Kalamazoo, MI: W. E. Upjohn Institute for Employment Research, 1981), p. 79.

2. Michael Aiken, Louis A. Ferman, and Harold B. Sheppard, Economic Failure, Alienation, and Extremism (Ann Arbor: University of Michigan Press, 1968). 
occupation. Noneconomic barriers to retraining include lower educational level associated with higher age plus considerable apprehension about returning to school.

It has been suggested that older workers have attempted to compensate for the liability of age by choosing job search assistance and placement programs. But, because of the unfavorable demographics of participants-older, less educated, fewer skills, more firm- or plant-specific skills-it is difficult to assess their success or failure. Early programs certainly did not appear to help participants. In the Mack Truck closing, only 5 percent of the placement program's participants found jobs through that channel. One study showed that those who received assistance in job search had post-program earnings of $\$ 7120$ annually compared with $\$ 7875$ shown by reemployed workers from the same plant who did not receive job search assistance. ${ }^{3}$ Any number of reasons can be advanced for this result, including the fact that participants had lower pre-program wages than nonparticipants, even though the lower skill and educational level, combined with other disadvantages, may actually have been marketed better by the placement program than participants could have managed on their own.

In the 1970s the idea of the job club, first developed for hard-to-employ clients, was used for displaced workers. There is some evidence to suggest that workers displaced from closings who participated in the well-known and successful Downriver Community Confer-

3. Gordus, Jarley, and Ferman, Plant Closings and Economic Dislocation, pp. 80-82. ence (DCC) Program 4 either resisted job clubs or became too dependent on the step-by-step process that the Azrin job club model requires. Job clubs assume two things. One is low motivation on the part of participants not only toward job search but toward work. This assumption of low motivation to search for lowpaying jobs may be accurate for displaced workers; low work motivation is not characteristic of displaced bluecollar workers. The other assumption is that there are jobs. Often the local labor market in an area with one or more plant closings simply has a job deficit.

However, when the local labor market has an adequate stock of jobs and when job search skills are taught to displaced workers from a plant closing, some success can be shown. During the first phase of the DCC Program, 56 percent of those who participated in the job search training, which was required of all participants, were reemployed.

If the sparse data we have provide any indications about successful versus unsuccessful job search approaches, it is that plant closing workers lack information about themselves and the labor market. Programs designed to increase their information and their job search skills do succeed when jobs exist. This suggests that plant closing workers do engage in a cost-benefit analysis, just as theory indicates job searchers do. Workers from plant closings will resist costly job search/retraining/relocation efforts in favor of those with lower costs.

4. Jane Kulik et al., Reemploying Displaced Workers: The Implementation of the Downriver Community Conference Economic Readjustment Program (Cambridge, MA: Abt Associates, 1982), pp. 9-11.

5. Ibid., pp. 9, 23-27. 
If one indisputable fact has emerged from research about plant shutdowns, it is that workers prefer to reenter the labor market close to home and that they will resist other higher-cost options until it is clear that no success at local job search will result for them.

\section{RELOCATION AND \\ RELOCATION ASSISTANCE PROGRAMS}

Relocation assistance can be available in two general forms after a plant closing. In some cases there are collectively bargained rights of transfer. There have been public programs as well, including the Trade Adjustment Assistance (TAA) provisions.

We have some interesting evidence showing that when both blue-collar and white-collar workers are displaced by a plant closing, white-collar workers have very different job search behavior than blue-collar workers. White-collar workers will begin job search very early and they will relocate for new jobs. ${ }^{6}$ These two characteristics may actually be related. The perceived failure of the early job search may very well be the impetus for a decision to relocate. This point may have relevance for blue-collar plant closing workers' decision making, since their later job search, undertaken when the labor market is already unable to absorb the results of the closure, may coincide with the end of unemployment benefits. Relocation might be chosen as the only available course at that time, and that type of uncommitted relocation followed by a return is a consistent feature of the plant closing relocation literature.

6. Gordus, Jarley, and Ferman, Plant Closings and Economic Dislocation, pp. 104-7.
A recent review of four relocation studies provides most of the available information about collectively bargained transfer programs. ${ }^{7}$ The studies cover a variety of plant closings, including auto, steel, rubber, glass, oil, truck manufacturing, meat packing, and food processing. In the truck-plant situation, management did not wish to facilitate transfer and through a variety of obstructive techniques reduced incentive to relocate. The strategy met with some success, and 10 percent chose to relocate. Despite management's attempt to reduce relocation, that $\mathbf{1 0}$ percent rate is not very low in comparison with others. In another case, where a provision allowed workers to move to the new location to try it out and then choose to stay or to accept termination, with severance pay-a policy planned to facilitate a good decision-the relocation rate was 17 percent.

The best collectively bargained relocation provision described in the literature included the retention of seniority rights at the new location. Retention of seniority in a relocation is an important benefit to workers, and the result of this transfer policy was the highest relocation rate in the literature, 22.7 percent. This policy was also costly, since moving expenses and one week's pay were also provided.

Even transfers, moves to an assured job with a known income, often result in a return home. In cases in which workers could relocate temporarily and return with no loss of severance, 15-20 percent returned. Even the transfer policy that protected seniority did not hold all the workers at the new site. In that case 25 percent moved back to the old

7. Ibid., pp. 104-17. 
location. Relocation, it must be noted, is highly correlated with wage gains. One study showed, for example, that relocators had an income gain of $\$ 3093$ compared with those who chose to reenter the local labor market. Of course, local labor market entrants may have closed the wage gap after gaining some experience in the new job or occupation.

Relocation is chosen, as one writer has noted, ${ }^{8}$ mostly by those who do not need to move. Comparative youth, comparatively high skill level, and comparatively high educational level are all associated with relocation. On average, the younger, more highly skilled, and better-educated have a better chance in any labor market. It is important to stress that the low relocation rates cited here are associated with assured and relatively comparable jobs. The effect of this assured job for the plant closing worker making the decision is to reduce uncertainty. The worker, in such cases, knows the benefit - the wage at the new locationagainst which to balance the economic and noneconomic costs of the move, something not available to those who relocate and then search for work.

A further point needs comment. Most of these studies were done in periods when the two-wage household was not as common as it is now. Early studies show that women almost never relocated, especially married women, since they were usually secondary wage earners and such a move was not often reasonable. The two-wage household is yet another disincentive for relocation as a major plant closing policy.

Public policy developed to facilitate relocation has not been particularly successful, as one might predict. Some

8. Ibid., p. 97. emphasis on relocation was developed during the Trade Adjustment Assistance (TAA) programming available to workers from trade-impacted industries. However, many of these workers were laid off as a result of massive layoffs and partial closures, and many, estimated to be between 70 and 80 percent, actually returned to the original employer. ${ }^{9}$ It is not surprising therefore that less than 6 percent of TAA participants elected to relocate with the moving expenses and other assistance available through that program. ${ }^{10}$ More recently, we find the relocation component of DCC providing a carefully designed and wellimplemented program to help those who wish to move after an initial trip to search for a job. After a job offer that meets the TAA guidelines-providing 80 percent of the former wage-is made, a lump sum for start-up costs, moving expenses for the family, transportation, and per diem were provided. Still, from August 1980 until the end of September 1981-DCC's first phase-52 participants, or 8 percent of the total enrollment, relocated. Of these, about 10-15 percent have returned. ${ }^{11}$

It is clear that, as a human resource policy, relocation works best-if it works at all-when it is collectively bargained. In that case, a major problemuncertainty - is reduced, while the costs are often reduced by moving-expense reimbursement. Moreover, the benefits the wage at the new site-are known. Yet, even in this case, when the costs and

9. Martin S. Feldstein, "Temporary Layoffs in the Theory of Unemployment," Journal of POlitical Economy, 84:937-57 (1976).

10. Walter Corson et al., Survey of Trade Adjustment Assistance Recipients (Princeton, NJ: Mathematica Policy Research, 1979).

11. Kulik et al., Reemploying Displaced Workers, pp. 27-32. 
benefits are known, and uncertainties reduced, relocation is consistently rejected. Fortunately, public policy has moved away from relocation as a human resource strategy. Whether or not the direction chosen is more productive remains to be seen.

\section{RETRAINING AND RETRAINING ASSISTANCE}

At the present time, public policy emphasizes retraining as the primary, if not the sole, solution to the problem of structural unemployment, including plant closings. Retraining, of course, simply represents another type of mobility. While those who relocate move geographically to obtain employment, those who retrain change occupations from declining sectors to growing occupations. Some theoretical formulations support retraining as an adjustment measure. The assumptions underlying such an approach include the idea that workers from plant closings may exhibit skill shortages that make them ill equipped for new jobs requiring different skills. Neither side of this assumption has been either proved or disproved. However, research currently in progress $^{12}$ has already provided evidence that one category of workers, displaced due both to plant closings and to layoffs, are not particularly short of skills in areas where jobs are expected to be. Recent estimates from the Bureau of Labor Statistics (BLS) for jobs to be created by 1990 give the occupations

12. Jeanne Prial Gordus et al., Labor Force Status, Program Participation, and Economic Adjustment of Displaced Auto Workers, University of Michigan Displaced Auto Worker Study Report no. 3 (Ann Arbor, MI: Institute of Science and Technology, 1984). specified in Table 1 as the sources of most new jobs.

Only three of these jobs-nursing, teaching, and truck driving-require any retraining. Certification demands some training for truck drivers, while nursing occupations require a serious and prolonged retraining effort. Many of these jobs, notably teaching, will not be available for several years. Still, one might reasonably argue that many jobs not yet created or imagined might arise and require skilled workers. However, without some idea of the content of these jobs, training programs cannot be designed except in the most general terms, with components that are broad based and flexible, such as mathematical and computer skills.

These microlevel concerns are often dismissed, since the idea of human capital is actually a macrolevel concept. Originally developed as a residual explanation for a rate of growth in the American economy that grew after World War II at a faster rate than capital inputs could explain, human capital explanations fared well when the returns to investment on education were higher than other returns on invested capital. That rate of return is now lower, but the idea still drives much program development. While it is true that private industry spends considerable funds for training, the level has been relatively low overall, totaling about 10 percent of the amount set aside for capital expenditures. $^{13}$

What is the record of retraining efforts associated with plant closings? As with other plant closing interven-

13. Pat Choate, Retooling the American Work Force: Issues and Federal Options (Washington, DC: Northeast-Midwest Institute, 1982). 
TABLE 1

TEN OCCUPATIONS WITH LARGEST JOB GROWTH, 1982-95

\begin{tabular}{lccc}
\hline & $\begin{array}{c}\text { Change in } \\
\text { Total Employment } \\
\text { (in thousands) }\end{array}$ & $\begin{array}{c}\text { Percentage of } \\
\text { Total Job Growth }\end{array}$ & $\begin{array}{c}\text { Percentage } \\
\text { Change }\end{array}$ \\
\hline Building custodians & 779 & 3.0 & 27.5 \\
Cashiers & 744 & 2.9 & 47.4 \\
Secretaries & 719 & 2.8 & 29.5 \\
General clerks, office & 696 & 2.7 & 29.6 \\
Salesclerks & 685 & 2.7 & 23.5 \\
Nurses, registered & 642 & 2.5 & 48.9 \\
Waiters and waitresses & 562 & 2.2 & 33.8 \\
Teachers, kindergarten & & & 37.4 \\
$\quad$ and elementary & 511 & 2.0 & 26.5 \\
Truckdrivers & 425 & 1.7 & 34.8 \\
Nursing aides and orderlies & 423 & 1.7 & \\
\hline
\end{tabular}

SOURCE: George T. Silvestri, John M. Lukasiewicz, and Marcus E. Einstein, "Occupational Employment Projection through 1955," Monthly Labor Review, 106(11):45 (Nov. 1983).

NOTE: Includes only detailed occupations with 1982 employment of 25,000 or more. Data for 1995 is based on moderate-trend projections.

tions, the data are not extensive, nor do they support close analysis. In general, the record has not been particularly encouraging. In an analysis of published literature on retraining programs to assist with plant closing displacement, it was noted that participation was low, ranging from 6 percent of the eligible workers at one site to 16.4 percent of those eligible at the plant closing site with the highest participation rate. ${ }^{14}$

Only the most general remarks can be made about these early retraining efforts. Women enrolled in disproportionate numbers. There are several plausible explanations for this, including the fact that women in two-worker households probably had lower opportunity costs for retraining while other options, such as relocation, were obviously less attractive to them than occupational mobility.

14. Gordus, Jarley, and Ferman, Plant Closings and Economic Dislocation, pp. 104-7.
It is important to note that the retraining literature also shows that retrainees do not have post-program wage rates as high as their earlier wage rates. Again, there are many explanations for that, but besides the obvious switch from high seniority, with high value placed upon firm-specific skills, to entry-level positions, there is a possible connection between the high rate of female participation in retraining and low wages. If retraining programs were developed for the lower-paying service occupations, men may have continued to decline to participate while women screened themselves into programs with placements in occupational areas with lower wages.

The BLS data shown in Table 1 seem, on the surface, to predict jobs that are low paying, in the service area, and traditionally associated with women. However, as we know, workers from plant closings tend to be chiefly male.

More recent programs have not yet been evaluated, although some analysis 
has been completed for some programs. In Table 2 we present some information about 14 examples of small and large programs featuring retraining, job counseling, and placement activities.

These examples of displaced-worker training programs, although many are still in progress and others are completed but not thoroughly evaluated, provide some information important for policy development. Programs that are closely geared to the requirements of the local labor market do well. In Bridgeport, in Des Moines, at the Downriver Community Conference, when displaced workers are trained for jobs that currently exist-and when that training is designed to relieve employers of training costs-the outcomes are good.

The implications of that predictable result are several. First, there must be jobs for which people are to be trained and there must be information about those jobs. Clearly, retraining programs are geared to labor markets with some opportunities, a situation that does not prevail in many areas of the country where plant closings continue.

A second implication is that when retraining is chosen as a major emphasis, and when post-training placement rates are important, choices about the most trainable participants are made. It is not clear, however, that even a majority of plant closing workers would be assessed as good material for retraining programs.

A third implication of the information presented in Table 2 is that programs that work cost money. Since resources are inadequate-although $\$ 3.7$ billion is authorized for the Job Training Partnership Act, only $\$ 0.1$ billion is specifically for displaced-worker programs-and displaced workers are plentiful-estimates range from hundreds of thousands to more than 2 million-there is a distinct mismatch between the funds available for retraining and the numbers to be served. The implication of that is equally clear; participation rates may not need to be increased in general, but participation of some will be encouraged while the retraining of others will not.

\section{PARTICIPATION, NONPARTICIPATION, AND THE NEW TRAINING INITIATIVE}

We have discussed participation extensively in this article, to the point at which it may seem as though participation has been the sole evaluative criterion. In fact, that is very nearly true, for we have few data about most retraining programs that have occurred in the past besides participation rates. However, since retraining has become the major, if not the sole, public policy response to plant closings and massive layoffs, placement rates will take on critical importance and will change the emphasis upon participation from how many participate to who the participants are.

In the past, blue-collar workers from plant closings have had virtually no mobility in their working lives. Apart from the indefinite layoff and the recall, most industrial workers have been rewarded for endurance and have sought stability within a relatively narrow job structure. Termination, even by the obviously permanent plant closing, often elicits a passivity that needs to be understood within the context of a work history that has rewarded workers for relinquishing their career development planning to others. This passivity is a perfectly reasonable response considering that plant closings occur in tight 


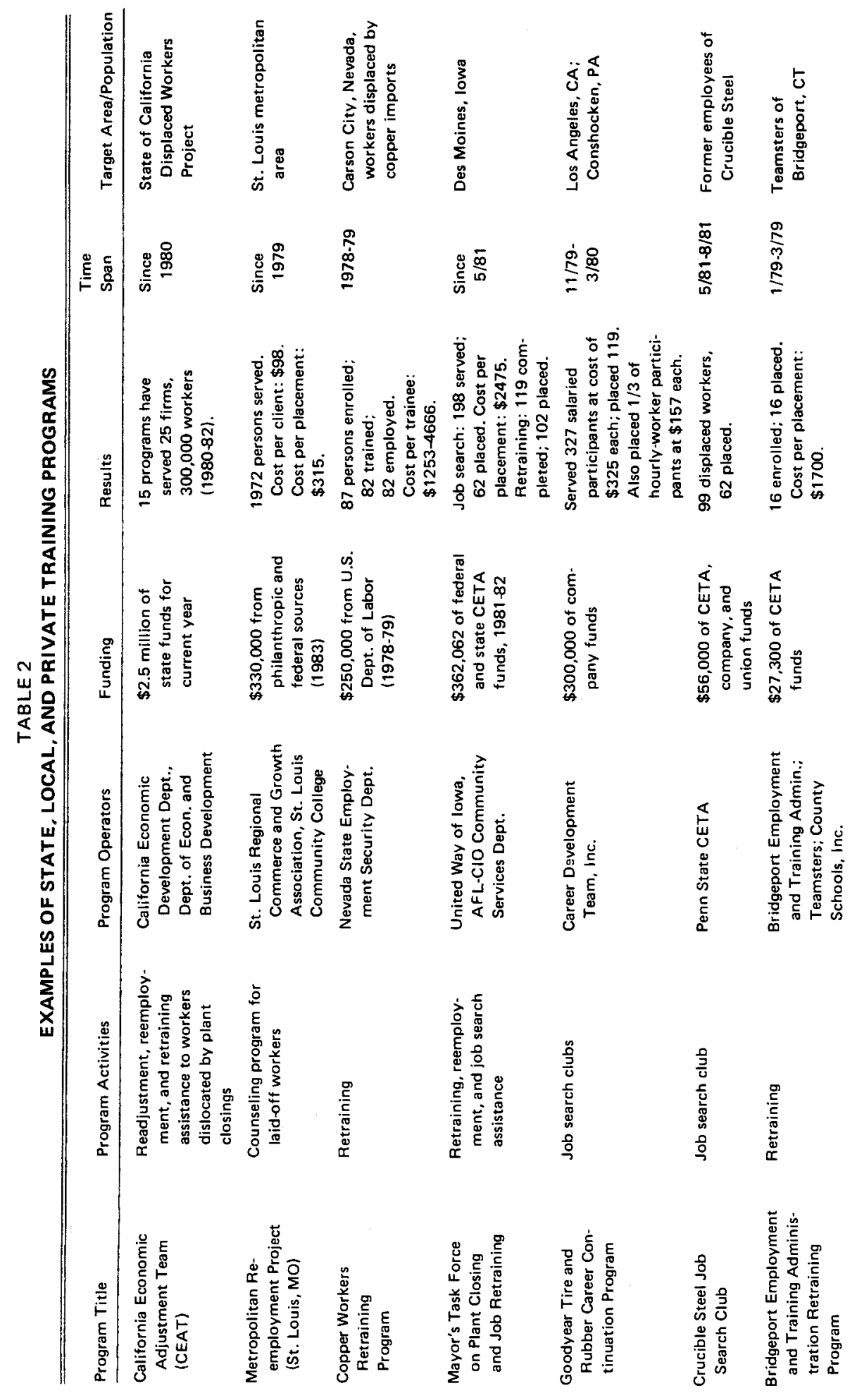




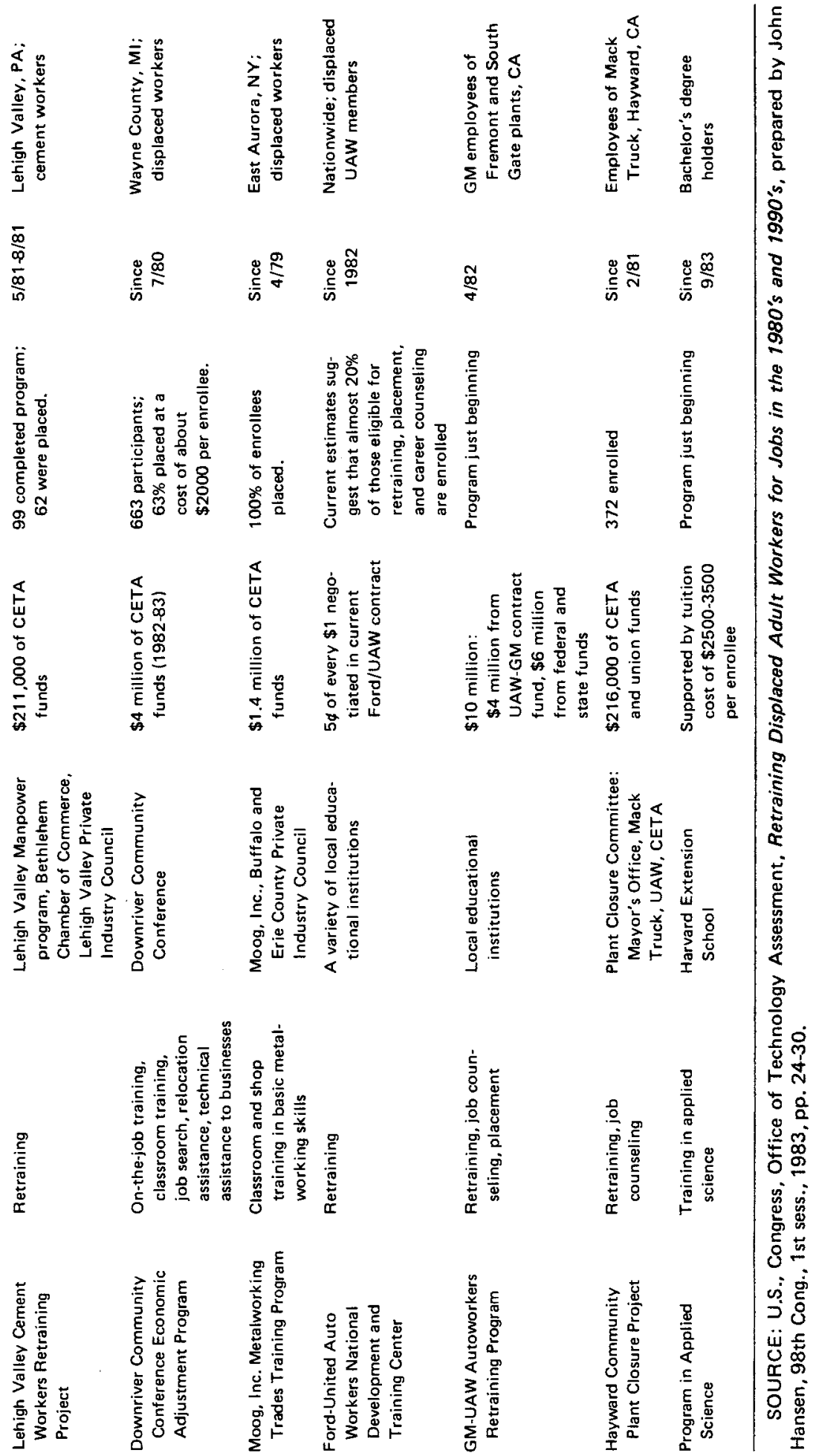


labor markets and benefits are provided to sustain income until other jobs surface that have the same characteristics and that reward the same attributes. Passivity, however, is obviously no longer appropriate.

In the past, most plant closing programs accepted the sorting of participants that the labor market provided. The result was, as the literature suggests, that those who could not or did not reenter the labor market directly and easily sought assistance through programs. Thus participation in retraining most often drew those who had a need for some assistance, those with lowerthan-average pre-closing wage rates and those with no opportunity to relocate and with low wage expectations, such as displaced women workers.

The current situation, in contrast, puts pressure upon providers, including those labor-management programs that are partly funded by government moneys, to recruit those who would not have participated in the past, namely, those better advantaged, all other things being equal, to find employment on their own. Such careful selection-and often limited selection as well-is not new to employment and training. However, it will become more critical as program refunding depends upon placement in a labor market where opportunity appears to have constricted considerably. Generally, it can be expected that participants in new training programs will be younger, with higher levels of skills-although probably not skilled workers per se, who will still have considerable opportunity - and with a higher level of educational attainment. This type of participation is precisely what theory would suggest as appropriate, for training costs will be lower due to higher levels of educability, and the investment will have a longer period to provide benefits to retrained workers and to the economy at large.

Once again, in contrast to the past, nonparticipants will be those who are less advantaged to begin with and for whom no other possibilities are likely. This new sorting process, which appears to be an inevitable result of the new program designs and objectives of retraining, has very serious implications indeed. For example, the absence of stipends attached to retraining means that those whose unemployment insurance benefits have been exhausted can retrain only at their own expense, using savings, the earnings of other family members, and / or the proceeds of full-time or parttime work. Very often, it is the older worker-less advantaged from some perspectives and often a poor investment bet for retraining - who has savings and a working spouse-often a wife whose homemaking responsibilities have been reduced as children have grown - who can take advantage of retraining, since some funds are available. The younger workers, those whose trainability and good prospects for placement and expected return on investment, originally sorted into retraining, will have fewer financial resources and will not be able to retrain.

Retraining programs therefore risk serving a small group whose personal and financial resources are extensivethose who, research has shown, do well without program participation. Program participation will not be possible for those with limited personal and/or financial resources who might have benefited. Thus scarce funds may be targeted to help those who need less help and may result in a less productive use of those funds than another strategy might permit. 
Other workers may be denied assistance because of local political considerations. It will be very difficult for local officials to move quickly to assist workers in a shutdown at an early stage when previous closings have left others unemployed. Those from earlier closings will have already exhausted their unemployment benefits. They will therefore have to work, leaving no time for retraining and thus creating a serious inequity.

A major concern voiced by leaders of minority groups has been the shift of funds and attention from the disadvantaged unemployed - who have never had a strong labor force attachment-to the displaced unemployed who have, until the layoff, been at a comparative advantage. Such a scenario would unfold with even fewer of the disadvantaged gaining training and subsequent employment since limited funds and contracting labor market opportunities will be won by displaced workers and lost to disadvantaged, hard-to-employ individuals. The result would be an enlargement of the permanent underclass.

Another scenario is beginning to unfold as well, this time within the ranks of the displaced workers from plant closings and massive layoffs. That is the possibility of competition among the displaced workers for the relatively few retraining and employment opportunities available, with the emergence of relatively few winners. Displaced workers from two of the major automobile firms are more likely to be winners because additional resources can be deployed for a range of educational opportunities and programs not available to other displaced workers. Women will fall into two groups. Those who are secondary wage earners may be advantaged by retraining, especially since many jobs in growth occupations are traditionally held by females. Single women with dependents and one income will be seriously disadvantaged.

In general, the winners will be those who are highly trainable and who also have either short durations of unemployment and continuing benefits or a high level of personal resources - in short those most likely to have relatively positive outcomes without assistance. The losers will be all the others, those whose plant closings occurred before retraining opportunities were available, those who are expected, because of age or education level, to be less likely candidates for high-level skill training, and those who have a high level of need for some type of plant closing assistance. From one viewpoint, this new restrictive policy may be convenient-though callous-since, without good labor market information and a high level of relevant skill training, only a few can be served, and the chances that these few can be placed are improved.

The human resource implications of plant closings have never been positive. Earnings losses, family and personal disruption, low levels of program participation, uneven levels of program effectiveness, and a patchwork set of responses have characterized the people, programs, and policies associated with plant shutdowns. But the external context has changed, making reemployment at even 50-60 percent of the former wage rate difficult for displaced industrial workers, even with some assistance. As the industrial structure has changed, public policy has also changed, moving from a patchwork response to an emerging consensus that retraining is the solution. Whether the basis of this consensus is a conviction that investment in human 
capital must pay off; whether it is founded on a conviction that displaced American workers, in the face of no compelling evidence, really do lack skills for emerging occupations requiring skills; or whether retraining looks like a good strategy because it buys time when there are not many jobs available anywhere is not clear. It is probably a combination of all of these.

However, the specific form taken by this new policy initiative has constraints. It focuses upon retraining and provides no stipends during retraining, thus selecting for the newly unemployed or the relatively highly advantaged displaced industrial worker. It has no other components to serve the needs of those who either do not select or are not selected for retraining programs. It substitutes the desire for programs with high placement levels for the operation of the labor market. Previously those who participated in programs were those in greater need since their job search efforts had not been rewarded and they turned to programs for assistance in reemployment and retraining. Now it is likely that those who need programs the least but who are most likely to contribute to those high placement rates will be chosen and, depending upon their personal resources and/or their willingness to retrain while working at survival jobs and / or their relatively recent unemployment, an even smaller number will actually retrain.

It is highly probable that many displaced industrial workers will, in this new era, fare worse than they would have at earlier periods, in part because of the external environment but also as a result of public policy that is clearly designed to provide advantages to those already advantaged. Ultimately, a larger group of permanently unemployed will result. These individuals will be blamed for their unemployment since they did not participate in the retraining programs that were supposedly available.

Considerable evidence has been developed to show that those who attribute responsibility for their unemployment to themselves and responsibility for reemployment to agencies outside themselves have the least success in job search. ${ }^{15}$ Agencies providing programs must either serve those most likely to succeed or risk failure; so those agencies, by avoiding failure and the blame for failure, help shift the blame to displaced workers.

\section{CONCLUSION}

When a plant shuts down, what choices will the displaced workers have? If they cannot retire, they will choose to retrain very rapidly or take their chances without retraining in the local labor market or elsewhere.

What will human resource programs do? Those programs will move rapidly to recruit the most trainable and the most reemployable individuals from the closing plant, so that retraining can take place while unemployment benefits are still available to retrainees.

What will happen under these circumstances? A very small proportion of the workers will actually take retraining and, depending upon the local labor market and the quality of the program, these few workers and some programs will be successful, but at the expense of the majority of the displaced workers.

Why? Our public policy has moved from a posture that disregarded the

15. Paul J. Andrisani, "Internal-External Attitudes, Personal Initiative, and the Labor Market Experience of Black and White Men," Journal of Human Resources, 12:308-28 (Summer 1977). 
human resource problems associated with plant closings. It either passively permitted or actively assisted a patchwork set of responses that served those who could not become reemployed easily through their own efforts. The new policy initiative attempts to draw these patchwork responses together and to promote, through a variety of institutions, retraining as the solution to this problem.

Since displaced workers are numerous and resource limitations have been imposed, selective recruitment for retraining is inevitable and replaces the operation of the labor market, which was the mechanism for program selection until recently. In the past, those whose protracted unemployment indicated that their chances in the labor market were poor selected themselves for program participation. Now, those individuals will probably suffer continued unemployment at best, and permanent unemployment is a real possibility for many of them.

What will be the result of this policy? Ultimately, the costs associated with this permanent unemployment and underemployment will be borne by the displaced workers and by the taxpayers. Continued deterioration of physical and mental health of these individuals and their families will, without the intervention of a more equitable and enlightened policy, place enormous burdens upon publicly funded medical care programs and upon income maintenance programs.

It is absolutely essential that both public and private costs associated with closings, as well as public and private benefits, be calculated and that an adequate share of these adjustment costs be borne by a combination of public and private sources. No one blanket policy will work in every instance. A variety of remedies are available, including shared work, reduced work weeks, phased shutdowns-all of which permit early job search and retraining. Assistance should be targeted to those who need it as well as to those who will succeed. Retraining can function at various levels, including the very basic reading, writing and computational skills needed by some workers as retraining for new jobs that require such skills, unnecessary in the old jobs. Protracted job search assistance and extensive job development is essential, and subsidies to employers who will provide ultimately profitable on-the-job training can be powerful incentives to hire some - though not a great many-displaced workers. For those-especially older workers-with good severance settlements and other lump-sum payments, programs can be established to help them - with or without collaboration from other displaced workers - to set up small business enterprises.

It is clear that little good information was developed from earlier plant closing interventions, and it is possible that this small amount of poor information has led to the development of a policy toward the human resource problems of plant shutdowns that is arguably worse than the earlier nonpolicy. Despite the difficulties, it is important that the results of this new restrictive and selective policy be studied closely so that its real costs in terms of permanent unemployment, underemployment, and associated personal disruptions are made very clear. Such information will be critical when it is finally possible to develop programs and policies to take serious steps toward reducing the problems associated with industrial restructuring. 